in pain scores in favour of the Treatment group $(\mathrm{p}=0.08)$ (Figure 1). There were no significant differences in terms of the percentage of responders $(p=0.32)$, or patients with LDA $(p=0.50)$ between the 2 groups at follow up. There were no significant differences in pain scores between groups at 3 and 6 months post-injection.

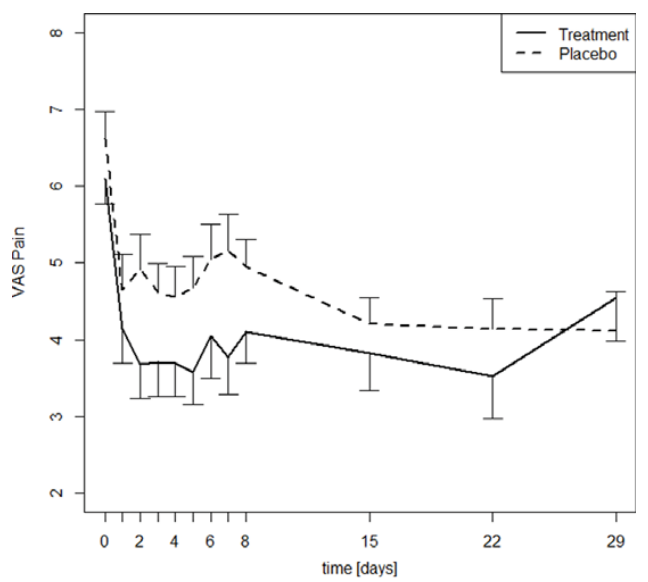

Conclusions: Local corticosteroid injection in the management of GTPS is only marginally effective for a few weeks. Given the lack of long-term improvement and the potential for cortisone-related side-effects, this intervention is of limited benefit.

Disclosure of Interest: None declared

DOI: 10.1136/annrheumdis-2017-eular.3458

\section{OP0272 CHRONIC LOW BACK PAIN AND ANXIETY: SIGNIFICANT DECREASE WITH GLUCOSAMINE-CHONDROITIN SULFATE TREATMENT IN A LARGE, COMMUNITY-BASED, PILOT, OPEN PROSPECTIVE INTERVENTIONAL STUDY}

G. Singh ${ }^{1}$, L. Alekseeva ${ }^{2}$, D. Goriachev ${ }^{3}$, A. Barinov ${ }^{3}$, E. Nasonov ${ }^{2}$, A. Mithal ${ }^{4}$ ${ }^{1}$ Gastroenterology and Hepatology, Stanford University, Woodside, United States; ${ }^{2}$ State NII of Rheumatology of Russian Academy of Sciences; ${ }^{3}$ First Moscow State University, Moscow, Russian Federation; ${ }^{4}$ ICORE, Woodside, United States

Background: Low back pain (LBP) is associated with 2.3, 2.2, and 1.6 times greater odds for mood disorders, anxiety disorders and alcohol abuse respectively (1). Continued anxiety may lead to a state of "learned helplessness", and both can propagate in a vicious cycle. Glucosamine-chondroitin sulfate (GCS) combination is widely used in the treatment of OA; however there are few prospective studies of its therapeutic merits in LBP.

Objectives: To study the efficacy of GCS in the decreasing anxiety in patients with chronic LBP in a large open pilot prospective study.

Methods: We enrolled patients $40-65$ years of age who had LBP for $>12$ weeks with pain intensity $>3$ on a $0-10$ point VAS in a single-arm, open-label prospective interventional study. Major exclusion criteria were the presence of fibromyalgia, spondylolisthesis, and alcohol and/or drug abuse. All patients were treated with ARTRA (combination glucosamine hydrochloride $500 \mathrm{mg}$ - chondroitin sulfate $500 \mathrm{mg}$ in tablet form; Unipharm Inc.) at a dose of $1 \mathrm{tab}$ bid for the first month and then 1 tab daily for the next two months. The primary endpoint was pain intensity as measured on a $0-10$ point VAS. Secondary endpoints included anxiety levels measured by Spielberger's State Trait Anxiety Inventory (STAI) adapted for Russia by Khanin (2). STAl evaluates the current "state" of anxiety, asking how respondents feel "right now," using items that measure subjective feelings of apprehension, tension, nervousness, worry, and activation/arousal of the autonomic nervous system as well as aspects of "anxiety proneness," including general states of calmness, confidence, and security ("trait"). Scores for each scale range from 20 to 80 , with higher scores indicating greater anxiety.

Results: A total of 8,598 subjects (mean age 52.1 years, $67.3 \%$ women, mean BMI 27.4) were enrolled in the study, and formed the intent-to-treat (ITT) population. All but 95 subjects $(1.1 \%)$ completed the study. Previously-reported ITT analysis with worst observation carried forward showed an improvement in pain at rest from mean $( \pm S D)$ of $5.2 \pm 1.9$ at study entry to $1.4 \pm 1.6$ at 3 months $(p<0.0001)$. Pain at movement decreased from $6.8 \pm 1.6$ to $2.2 \pm 1.8(p<0.0001)$. There was a strong correlation between increasing baseline STAI scores and baseline pain at rest and movement (both $p<0.0001$ ). After 12 weeks of GCS treatment, STAI "state" anxiety scores dropped from $49.3(95 \% \mathrm{Cl} 49.1$ to $49.6)$ to $35.8(95 \% \mathrm{Cl} 35.6-36.0)(\mathrm{p}<0.0001)$. A similar reduction was seen in "trait" anxiety scores from $48.3(95 \% \mathrm{Cl} 48.0-48.5)$ to $39.6(95 \% \mathrm{Cl} 39.3-39.8)$ $(p<0.001)$.

Conclusions: Although open and uncontrolled, this large pilot community-based study shows dramatic reductions in pain and anxiety (both "state" and "trait") in patients with LBP treated with GCS. With its benign safety profile, GCS therapy deserves serious evaluation in the management of LBP in a prospective randomized double-blinded clinical trial.
References:

[1] Demyttenaere, K., et al., Mental disorders among persons with chronic back or neck pain. Pain, 2007. 129:332-42.

[2] Spielberger, C. D. (1989). State-Trait Anxiety Inventory: A comprehensive bibliography. Palo Alto, CA: Consulting Psychologists Press.

Disclosure of Interest: G. Singh Grant/research support from: Unipharm Inc., L. Alekseeva: None declared, D. Goriachev Consultant for: Unipharm Inc., A. Barinov: None declared, E. Nasonov: None declared, A. Mithal: None declared DOI: 10.1136/annrheumdis-2017-eular.2642

\section{OP0273 A RETROSPECTIVE DATABASE STUDY OF ONE-YEAR ADEHERNCE AND PERSISTENCE WITH PHARMACOLOGICAL THERAPY AMONG FIBROMYALGIA PATIENTS IN ISRAEL}

D. Weitzman ${ }^{1,2}$, D. Ben-Ami Shor ${ }^{2,3}$, S. Dahan ${ }^{2,4}$, Y. Bar-On ${ }^{5}$, V. Shalev ${ }^{1,2}$, G. Chodick ${ }^{1,2}, \mathrm{H}$. Amital ${ }^{2,4}$. ${ }^{1}$ Epidemiology and Database Resaerch, Maccabitech, Maccabi Healthcare Services; ${ }^{2}$ Sackler Faculty of Medicine, Tel Aviv University, Tel Aviv; ${ }^{3}$ Department of Gastroenterology; ${ }^{4}$ Department of Medicine B, Zabludowicz Center for Autoimmune Diseases, Sheba Medical Center, Tel Hashomer; ${ }^{5}$ Department of Medicine E, Tel-Aviv Sourasky Medical Center, Tel Aviv, Israel

Background: Fibromyalgia (FM) is a chronic debilitating disorder characterized by widespread musculoskeletal pain often accompanied by fatigue, allodynia and hyperalgesia. Literature is scarce regarding adherence to pharmacologic treatments available for FM patients.

Objectives: To assess one-year persistence and adherence with therapy among patients with FM and to identify factors associated with therapy discontinuation. Methods: Using the comprehensive computerized database of Maccabi Healthcare Services, a large healthcare services provider in Israel, all adults ( $\geq 21 \mathrm{yrs}$ ) diagnosed with FM between 2008 and 2011 were identified. FM medications included the anti-convulsant pregabalin, SSRI/SNRI and tricyclic antidepressants. Time to treatment discontinuation, defined as a gap of $\geq 120$ days in medication supply days, and proportion of days covered (PDC) with FM-specific therapies during one year from the first dispense were analyzed. Multivariable logistic regression models were constructed to analyze factors associated with low (PDC $<20 \%$ ) and high (PDC $\geq 80 \%$ ) adherence.

Results: Overall 3932 eligible FM patients were identified, $88.7 \%$ females, mean) SD (age $=49.2$ (12.7). Pre-diagnosis use of medications of interest was documented in $41 \%$ of the patients. Of the remaining $2312,56.1 \%$ were issued a prescription in the year following diagnosis and $45.0 \%$ dispensed at least on medication. One-year discontinuation reached $79.3 \%$ overall, and was highest for tricyclic antidepressants and lowest for SSRI/SNRI antidepressants (Table 1). Over one half of the patients $(60.5 \%)$ were poorly adherent $(\mathrm{PDC}<20 \%)$ during the year and only $9.3 \%$ were highly adherent (PDC $\geq 80 \%$ ). Low adherence was less prevalent among patients diagnosed with migraines (OR=0.62, 95\% $\mathrm{Cl}: 0.48-$ $0.80)$ or with both depression and anxiety $(\mathrm{OR}=0.55 ; 0.40-0.76)$. High adherence was positively associated with socio-economic status ( $p$-for-trend=0.022).

Table 1. Medications prescribed and dispensed in the first year from diagnosis, proportion discontinuing and time to discontinuation in the year following first dispense $(\mathrm{N}=1296)$

\begin{tabular}{|c|c|c|c|c|}
\hline \multirow[t]{2}{*}{ Drug group } & \multirow{2}{*}{$\begin{array}{l}\text { Prescribed } \\
\mathrm{N}(\%)\end{array}$} & \multirow{2}{*}{$\begin{array}{c}\geq 1 \text { dispense } \\
\mathrm{N}(\%)^{\star}\end{array}$} & \multicolumn{2}{|r|}{ Discontinued } \\
\hline & & & $\mathrm{N}(\%)^{\star \star}$ & $\begin{array}{c}\text { Days to discontinuation } \\
\text { Median (IQR) }\end{array}$ \\
\hline Anti-Convulsants & $313(24.1 \%)$ & $228(72.8 \%)$ & $186(81.6 \%)$ & $30(30-106)$ \\
\hline SSRI/SNRI antidepressants & $606(46.7 \%)$ & $471(77.7 \%)$ & $347(73.7 \%)$ & $41(30-171)$ \\
\hline Tricyclic antidepressants & 767 (59.1\%) & $601(78.4 \%)$ & $547(91.0 \%)$ & $30(30-90)$ \\
\hline Any drug & $1296(100 \%)$ & $1041(80.3 \%)$ & 825 (79.3\%) & $40.5(30-146)$ \\
\hline
\end{tabular}

${ }^{*}$ Percent of patients with at least one dispense out of those prescribed, e.g. $228 / 313 \times 100=72.8 \%$ for anti-epileptic drugs. ${ }^{*} \%$ of those with $\geq 1$ dispense.

Conclusions: Persistence and adherence with FM therapy in the year following diagnosis is remarkably low. Further research is needed to assess ways to improve continuation with therapy among FM patients.

Disclosure of Interest: None declared

DOI: 10.1136/annrheumdis-2017-eular.4578

\section{OP0274 FIBROMYALGIA IN REAL LIFE: A NATIONAL FRENCH WEB-BASED SURVEY IN 4516 PATIENTS}

F. Laroche ${ }^{1}$, J. Guérin ${ }^{1}$, D. Azoulay ${ }^{1}$, J. Coste ${ }^{2}$, S. Perrot ${ }^{3}$. ${ }^{1}$ Pain Department, Hospital university Saint Antoine, ${ }^{2}$ Biostatistics, Hospital University Hotel Dieu; ${ }^{3}$ Pain Department, Hospital University Cochin, Paris, France

Background: Fibromyalgia (FM) is the most frequent widespread chronic pain disorder (1,6\% of the French population) (1). The medical and socioeconomic burden is high and severity depends on medical status and symptoms as defined by the OMERACT criteria (2). Most of the studies are performed in specialized centers, recruiting the most severe patients, but very few data exist on its real impact on daily life.

Objectives: The aims were to collect demographic data, symptoms, function, diagnosis, management strategies and health care utilization in real life, in a large population, and to determine clusters of patients. 
Methods: A large internet-based national survey of people suffering from FM was developed by a national patient association (Fibromyalgie-SOS Association) on their website, in France in 2014. The survey included 103 qualitative and quantitative questions that were developed by 3 medical experts (including rheumatologists) and patients.

Results: The questionnaire was completed by 4516 people. Respondents were predominantly middleaged (48 yrs) females (93\%), most of whom had FM symptoms duration for 12 years and a diagnosis for 5 years. Diagnosis was made by a rheumatologist in $54 \%$ of the cases. The symptoms were concordant with the OMERACT domains (chronic pain, fatigue stiffness and other FM-associated symptoms) as previously published by Bennett in 2007 (3). The mean FIQ (Fibromyalgia Impact Questionnaire) score was 51 (0-100). 55\% were currently working but $65 \%$ of them have been on sick leave in the 12 previous months. FIQ was mostly impacted by injustice feeling (+4.5), part time job $(+2.4)$ and low income - less than 1000 euros monthly $(+2.3)$ (linear regression).

Somatic comorbidities were mostly osteoarthritis (49\%). Psychological comorbidities were injustice feeling (77\%), cognitive symptoms $(62 \%)$, anxiety $(52 \%)$ and depression (48\%). Initiating factors were reported by $73 \%$ of them: physical $(50 \%)$ and/or psychological (76\%). Aggravating factors included excess of activities, conflicts, traumatism and displacement. Treatments were provided by general practitioner $(85 \%)$, physiotherapist $(63 \%)$, rheumatologist $(54 \%)$ and osteopathic manual practitioner $(41 \%)$. Treatment was prescribed in $76.6 \%$ of the patients, including paracetamol alone $(51.4 \%)$, paracetamol and weak opioids $(64 \%)$, strong opioids (20.1\%), antidepressants (81.5\%), antiepileptic agents $(54.5 \%)$, nonsteroidals NSAIDs (53.8\%), anxiolytics (52.4\%) and steroids (12.8\%).

Conclusions: This unique descriptive survey in a large population provides data on symptoms, emotional distress, prescribing habits and impact of FM on daily life and work. Results show that FM is altered by emotional (including injustice feeling) and socio-economic factors.

\section{References:}

[1] Perrot S, Vicaut E, Servant D, Ravaud P. Prevalence of fibromyalgia in France: a multi-step study research combining national screening and clinical confirmation: The DEFI study (Determination of Epidemiology of Fibromyalgia). BMC Musculoskeletal Disorders 2011; 12:224.

[2] Mease P, Clauw D, Arnold L. and the OMERACT Fibromyalgia Working Group. The Journal of Rheumatology, 2011; 38: 1487-95.

[3] Bennett R. Jones J, Turk D, Russell I, Matallana L. An internet survey of 2,596 people with fibromyalgia. BMC Musculoskeletal Disorders 2007, 8:27: 1-11.

Disclosure of Interest: None declared

DOI: 10.1136/annrheumdis-2017-eular.3390

\section{OP0275 FIBROMYALGIA PREVALENCE AND IMPACT ON DISEASE ACTIVITY SCORES IN RHEUMATOID ARTHRITIS PATIENTS WHO ARE UNRESPONSIVE TO BIOLOGICAL TREATMENT}

L.J. Ghib $^{1}$, M.M. Tamas ${ }^{1}$, I. Felea ${ }^{2}$, L. Damian ${ }^{2}$, I. Filipescu ${ }^{1}$, A. Mociran ${ }^{2}$ S.-P. Simon ${ }^{1}$, L. Muntean ${ }^{1}$, S. Rednic ${ }^{1}$. ${ }^{1}$ Rheumatology, "Iuliu Hatieganu" University of Medicine and Pharmacy; ${ }^{2}$ Rheumatology, Emergency County Clinical Hospital, Cluj Napoca, Romania

Background: Rheumatoid arthritis (RA) treatment uses a treat-to-target strategy and disease assessment is based on disease activity scores (DAS) such as the DAS28 ${ }^{1}$. Biological drugs have proven highly effective for RA treatment in clinical studies $^{2}$, however, in real life settings, comorbidities such as fibromyalgia (FM) might influence treatment response assessed by DAS28.

Objectives: In this study we determined FM prevalence and the impact on disease activity scores in patients with RA undergoing biological treatment and if higher tender joint (TJC) correlates with lower pain threshold in patients with active RA who did not satisfy FM criteria.

Methods: We performed a cross sectional study on RA patients undergoing biological treatment who presented in our department for a 6 month period. DAS28 was calculated for all patients. FM diagnosis was considered positive if patients satisfied both the ACR 1990 and ACR 2010 FM Criteria. Pain pressure thresholds (PPT) were measured at the level of the medial knee joint line, mid sternum and middle of the tibia with a manual dolorimeter. Depression, Anxiety, Stress 21 scale (DASS21) and Health Assessment Questionnaire (HAQ) were applied to all patients.

Results: 112 patients were included, $84.8 \%$ women, mean age 55.6 (SD 11.6) with a mean disease duration of 14.5 (SD 8.5) years. Acording to DAS28ESR scores $54(48.2 \%)$ had moderate disease activity and $26(23.2 \%)$ had high disease activity. 17 (21.5\%) of patients with DAS28ESR scores over 3.2 satisfied FM criteria. FRA and RA groups did not differ significantly concerning age, disease and biological treatment duration, seropositivity, BMI or DASS21 scores. FRA patients had significantly higher values for DAS28 ESR, DAS28 CRP, PGH and $H A Q$, but similar values for SJC, ESR and CRP compared to RA patients (Table 1). In RA patients without FM, TJC correlated significantly with number of trigger points $(r=-0.3)$, PPT at knee $(r=-0.4)$, sternum $(r=-0.3)$ and tibial level $(r=-0.2)$.

Conclusions: Fibromyalgia is present in a significant percent of patients who are unresponsive to biological treatment as assessed by DAS28 score. Subjective components of DAS28 are significantly higher in FRA compared to RA patients, suggesting that disease assessment should be performed using objective measures in these patients. In patients with active disease despite biological
Table 1. DAS28 components for RA and FRA patients

\begin{tabular}{lccc}
\hline & RA $(\mathrm{n}=63)$, mean $(\mathrm{SD})$ & FRA $(\mathrm{n}=17)$, mean $(\mathrm{SD})$ & $\mathrm{P}$ value \\
\hline PGH & $49.9(19.8)$ & $68.8(17.2)$ & $<0.001$ \\
TJC & $5(3,9)$ & $10(8.5,17.5)$ & $<0.001$ \\
SJC & $2(1,4)$ & $2(1,5)$ & 0.8 \\
ESR & $27.5(19)$ & $32.8(23)$ & 0.4 \\
CRP & $8.8(14.4)$ & $12.8(15.6)$ & 0.2 \\
DAS28 ESR & $4.6(1.08)$ & $5.5(1.05)$ & 0.003 \\
DAS28CRP & $3.99(1)$ & $4.94(1.09)$ & 0.002 \\
HAQ & $1.2(0.5)$ & $1.7(0.6)$ & 0.002 \\
\hline
\end{tabular}

PGH - patient global health, TJC -tender joint count, SJC - swollen joint count, ESR - erythrocyte sedimentation rate, CRP - $C$ reactive protein.

treatment whitout FM, lower pain thresholds are correlated with TJC, suggesting a possible involvement of central pain mechanisms.

References:

[1] Smolen JS, et al. Treating rheumatoid arthritis to target: recommendations of an international task force. Ann Rheum Dis. 2010;69(4):631-637.

[2] Tvete IF, et al. Comparing Effects of Biologic Agents in Treating Patients with Rheumatoid Arthritis: A Multiple Treatment Comparison Regression Analysis. PLoS One. 2015;10(9):e0137258.

Disclosure of Interest: None declared

DOI: 10.1136/annrheumdis-2017-eular.5430

\section{LB0001 INTRADISCAL GLUCOCORTICOID INJECTION FOR PATIENTS WITH CHRONIC LOW BACK PAIN ASSOCIATED WITH ACTIVE DISCOPATHY: A RANDOMIZED TRIAL}

C. Nguyen $^{1}$, I. Boutron ${ }^{1}$, G. Baron ${ }^{1}$, K. Sanchez ${ }^{2}$, C. Palazzo ${ }^{1}$, R. Benchimol ${ }^{2}$, G. Paris ${ }^{1}$, E. James-Belin ${ }^{2}$, M.-M. Lefèvre-Colau ${ }^{1}$, J. Beaudreuil ${ }^{3}$

J.-D. Laredo ${ }^{3}$, A. Béra-Louville ${ }^{4}$, A. Cotten ${ }^{4}$, J.-L. Drapé ${ }^{1}$, A. Feydy ${ }^{1}$

P. Ravaud ${ }^{1}$, F. Rannou ${ }^{1}$, S. Poiraudeau ${ }^{1}$. ${ }^{1}$ Université Paris Descartes;

${ }^{2}$ Assistance Publique - Hôpitaux de Paris; ${ }^{3}$ Université Paris Diderot, Paris,

${ }^{4}$ Université Lille 2, Lille, France

Background: Active discopathy is associated with a specific phenotype of chronic low back pain (cLBP). Local inflammation has a role in active discopathyassociated symptoms (1).

Objectives: To assess the efficacy of a single glucocorticoid intradiscal injection (GC IDI) in cLBP patients with active discopathy.

Methods: We conducted a prospective, parallel-group, double-blind, randomized controlled study in 3 tertiary care centers in France. 135 cLBP patients with active discopathy on MRI were enrolled. They received a single GC IDI (25 mg prednisolone acetate) during discography $(n=67)$ or discography alone $(n=68)$. The primary outcome was the percentage of patients with LBP intensity in the previous $48 \mathrm{hr}<40$ on an 11-point numeric rating scale (NRS, 0 no pain - 100 maximal pain) at 1 month. The main secondary outcomes were LBP intensity and persisting active discopathy on MRI at 12 months post-intervention, and spine-specific limitations in activities, health-related quality of life, anxiety and depression, employment status and analgesics and non-steroidal anti-inflammatory drugs consumption at 1 and 12 months.

Results: All randomized patients were included in the primary efficacy analysis At 1 month, the percentage of responders (LBP intensity $<40$ ) was higher in the GC IDI than control group (36/65 [55.4\%] vs 21/63 [33.3\%]; absolute risk difference [95\% confidence interval] 22.1 [5.5;38.7]); $p=0.009$. In the sensitivity analysis, mean reduction $[95 \% \mathrm{Cl}$ ] in LBP intensity from baseline to 1 month was greater in the GC IDI group compared to the control group (-32.5 [-38.2;-26.8] vs $-17.5[-23.3 ;-11.7]$, respectively; absolute difference [95\% Cl] $-15.0[-22.9 ;-7.1]$, $\mathrm{p}<0.001)$

At 1 month, the percentage of patients reporting an improvement in spine-specific limitations in activities was higher in the GC IDI than control group (55/65 [84.6\%] vs 34/63 [54.0\%]; absolute risk difference [95\% Cl] 30.5 [15.7; 45.2], $\mathrm{p}<0.001$ ). The 2 groups did not differ in LBP intensity at 12 months and in most of the secondary outcomes at 1 and 12 months. 102/119 (85.7\%) patients would agree to a second intervention. We found no cases of rapidly destructive disc disease or intervertebral disc calcifications.

Conclusions: In active discopathy-associated CLBP, a single GC IDI reduces LBP at 1 month post-intervention but not at 12 months.

Registration: ClinicalTrials.gov number NCT00804531 (First received: December 8, 2008. Last updated: June 23, 2016).

References:

[1] Nguyen C, Poiraudeau S, Rannou F. From Modic 1 vertebral-endplate subchondral bone signal changes detected by MRI to the concept of 'active discopathy'. Ann Rheum Dis. 2015 Aug;74(8):1488-94.

Acknowledgements: The study was funded by a research grant from the French Ministry of Health (Programme Hospitalier de Recherche Clinique, project no. P070157). The authors thank URC-CIC Paris Descartes Necker/Cochin (Christelle Auger and Nellie Moulopo) for implementation, monitoring and data management of the study.

Disclosure of Interest: None declared

DOI: 10.1136/annrheumdis-2017-eular.7062 